\title{
Revista \\ UNEMAT de Contabilidade
}

v. 9, n. 18,2020

\section{ACCOUNTABILITY DA PREFEITURA MUNICIPAL DE PINHAIS E A ADEQUAÇÃO DA LEI COMPLEMENTAR 131/2009}

\author{
Nome \\ Divane Dias dos Santos Nascimento \\ Instituição/Afiliação \\ INSTITUTO FEDERAL DO PARANA- IFPR CAMPUS CURITIBA \\ País \\ Brasil \\ Contato principal para correspondência: divane.nascimento@ifpr.edu.br \\ Nome \\ Instituição/Afiliação \\ País \\ Nome \\ Instituição/Afiliação \\ País \\ Paula Cristina da Silva \\ Instituto Federal do Paraná - IFPR Campus Curitiba \\ Brasil \\ Herbert Elemar Schindzielors \\ Instituto Federal do Paraná - IFPR Campus Curitiba \\ Brasil
}

\section{RESUMO}

No Brasil desde 2010, a União, os Estados, o Distrito Federal e os Municípios com mais de 100.000 (cem mil) habitantes são obrigados a implantar dispositivos que ampliam a transparência da gestão dos recursos públicos por meio da Lei Complementar $\mathrm{N}^{\circ} 131 / 2009$. O objetivo da pesquisa foi identificar se há Accountability na Prefeitura de Pinhais, no estado do Paraná, sob aspectos econômicos e financeiros, conforme a Lei complementar $\mathrm{N}^{\circ} 131 / 2009$. A pesquisa é, bibliográfica, qualitativa e a técnica utilizada foi um checklist, composto por 36 itens, sendo, 24 itens sobre aspectos econômicos, divididos entre receitas e despesas, e 12 itens sobre aspectos financeiros. Os resultados demonstraram que há um Accountabillity parcial na Prefeitura de Pinhais, pois a mesma não atendeu a Lei em sua integralidade.

Palavras-chave: Portal Eletrônico. Transparência. Lei 131/2009. Accountability. 


\title{
Revista \\ UNEMAT de \\ Contabilidade
}

v. 9, n. 18,2020

\begin{abstract}
In Brazil since 2010, the Union, the States, the Federal District and the Municipalities with more than 100,000 (one hundred thousand) inhabitants are obliged to implement devices that increase the transparency of the public resources management through Complementary Law No. 131/2009. The objective of this study is to identify if there is an application of Accountability in Pinhais Municipality, at Paraná State, about economic and financial aspects. The research is bibliographic, qualitative and the checklist technique was used, consisting in 36 items, 24 items on economic aspects, divided between income and expenses, and 12 items on financial aspects. The results showed that there are parcial Accountabillity in Pinhais, as it did not fully comply with the Law.
\end{abstract}

Keywords: Electronic Portal. Transparency. Law 131/2009. Accountability.

\section{INTRODUÇÃO}

A forma como os recursos públicos são geridos e a publicidade da prestação de contas destes recursos aos cidadãos, pode ser realizada e visualizada por meio da Accountability (FERREIRA, SILVA, SILVA, 2014).

Os interesses dos governantes e dos cidadãos podem nem sempre estar alinhados ao longo da história no âmbito do Estado. Kondo et al. (2002), destacaram que devem ser definidos preceitos abrangentes para uma gestão transparente e eficiente por meio de políticas públicas e também a utilização de um sistema automatizado integrado, como estrutura legal e ser aberto a toda a sociedade.

Historicamente, a reforma administrativa do Estado no Brasil, elaborada em 1995, possibilitou a modernização das estruturas administrativas, com a implementação do mecanismo de divulgação da informação.

Com a aprovação da Lei Complementar no 131/2009, sancionada em 27 de maio de 2009, também conhecida como Lei de Transparência Pública, um adendo à Lei de 


\section{Revista \\ UNEMAT de \\ Contabilidade}

v. 9 , n. 18,2020

Responsabilidade Fiscal (Lei Complementar $\mathrm{N}^{\mathrm{o}}$ 101/00, de maio de 2000), inseriu dispositivos que ampliam a transparência da gestão dos recursos públicos.

A Lei de Transparência Pública determinou a liberação ao pleno conhecimento e acompanhamento da sociedade, em tempo real, de informações pormenorizadas sobre a execução orçamentária e financeira, da União, dos Estados, do Distrito Federal e dos Municípios, em meios eletrônicos de acesso público. Assim sendo, esta Lei pode ser catalisadora da revolução no relacionamento entre Estado e sociedade, no tocante ao monitoramento dos recursos públicos e verificar as suas aplicações (BICALHO, 2009).

Partindo da premissa de que a administração pública deve estar voltada para o gerenciamento eficiente e transparente dos recursos públicos, que a internet é uma ferramenta importante na redução de assimetrias informacionais entre governo e a sociedade, e que diante dos atos dispostos na Lei Complementar Nº131/2009 há necessidade de adequação dos entes administrativos, surgiu à problemática do estudo: há Accountability na Prefeitura de Pinhais sob aspectos econômicos e financeiros conforme a Lei Complementar $\mathrm{N}^{\circ} 131 / 2009$ ?

Para responder essa pergunta, o presente trabalho tem como objetivo identificar se há Accountability na Prefeitura de Pinhais sob aspectos econômicos e financeiros conforme a Lei Complementar $N^{o} 131 / 2009$, que estabelece a transparência das normas de finanças públicas voltadas para a responsabilidade da gestão fiscal. Para tanto, busca-se apresentar receitas, despesas e relatórios financeiros baseados na referida Lei, aos quais todas as cidades acima de 100 mil habitantes são obrigadas a atender os dispositivos da Lei desde 2010 na sua integralidade.

A pesquisa justifica-se na premissa de que a aplicabilidade da Accountability na esfera pública, principalmente na esfera pública municipal, é uma ferramenta de gestão que auxilia o gestor público na tomada de decisão. Também, para garantir que seja atingido o interesse público em todas as ações dos gestores públicos e que estas sejam realizadas de 


\section{Revista \\ UNEMAT de \\ Contabilidade \\ v. 9, n. 18,2020}

acordo com os princípios da administração pública, que são legalidade, impessoalidade, moralidade, publicidade e eficiência (PEREIRA, 2004). Assim, o gestor ao não cumprir a legislação pública está sujeito a sanções, entre elas, a perda da função pública, a suspensão dos direitos políticos de três a cinco anos e pagamento de multa civil de até cem vezes o valor da remuneração percebida pelo agente.

Para tanto, a fim de cumprir o objetivo proposto, o estudo está organizado da seguinte forma: Introdução; Referencial teórico: administração pública e governança pública, Accountability na gestão pública, Lei complementar $n^{\circ}$ 131, de 27 de maio de 2009, Decreto $\mathrm{n}^{\mathrm{o}} 7.185$, de 27 de maio de 2010 e pesquisas anteriores sobre o tema; Metodologia; Análise e Discussão dos resultados; Considerações Finais, e, Referências.

\section{REFERENCIAL TEÓRICO}

\subsection{Administração Pública e Governança Pública}

Conforme a Constituição Federal de 1988, art. 1º, parágrafo único “[...] todo poder emana do povo, que o exerce por meio de representantes eleitos diretamente [...] (BRASIL, 1988, p.01)." Portanto, é em nome deste artigo que os representantes escolhidos pela sociedade, deveriam gerir a coisa pública e assim representar cada cidadão, exercendo tal poder através da administração pública.

Para Waldo (1971) o conceito de administração pública está ligado à organização e a gerência de pessoas e recursos, para a consecução dos objetivos de um governo. Já para Harmon e Mayer (1999) administração pública é a ocupação de todos envolvidos atuando em nome do povo ou da sociedade, de forma legal e cujas ações terão consequências para os indivíduos e grupos sociais. 


\section{Revista \\ UNEMAT de \\ v. 9 , n. 18,2020 \\ Contabilidade}

Diante de todas as mudanças de mentalidade e avanço de tecnologia, escândalos corporativos e públicos, a administração atualmente aplicada ao setor público baseia-se em princípios básicos da administração como organização, planejamento, comando e controle. Com a implantação do modelo gerencial, adotado na administração privada, que passou a ter uma postura de serviço estritamente voltada aos anseios do cidadão, com maior transparência e ética nos negócios públicos, tendo como propósitos o aumento da eficácia, eficiência e efetividade da administração pública (PEREIRA, 2004).

O modo de pensar e gerir a máquina pública mudou durante o tempo. Um conceito desenvolvido foi o de governança pública, princípio básico e prático, conduz a administração pública ao alcance da eficiência e efetividade, nos seus resultados, através de um melhor gerenciamento dos seus processos e de suas atividades, promovendo a prestação de contas responsável e a transparência de suas ações (BIZERRA, 2011).

A governança pública é um modelo de política de desenvolvimento orientada por elementos estruturais, como gestão, responsabilidade, transparência e legalidade do setor público, considerado necessário ao desenvolvimento de toda sociedade (KISSLER, HEIDEMANN, 2006).

Bellver e Kaufmann (2005) fazem uma relação interessante entre informação e transparência, que em uma sociedade democrática esses dois elementos são considerados direitos humanos fundamentais. Para O’Donnel (1991) é obrigação do governante prestar contas dos seus atos, com necessária transparência, mediante procedimento democrático, para que a cidadania possa avaliar a sua gestão, questionar ou até punir se comprovada a inconformidade, ou descumprimento da sua responsabilidade, aspecto básico da Accountability. 


\section{Revista \\ UNEMAT de \\ v. 9, n. 18,2020 \\ Contabilidade}

Apesar da quantidade de informações e da diversidade dos meios de acessos estarem crescendo, segundo Silva (2009), o grau de transparência para os atores políticos não alcançaram o nível ideal, no ponto de vista da sociedade.

Transparência e princípio da publicidade em termos jurídicos são coisas diferentes. A publicidade é atendida no ato da publicação no veículo oficial de imprensa, já a transparência não se limita com mero cumprimento de formalidade. Transparência deixa exposta, visível, sem barreira ao conhecimento (GOMES FILHO, 2005).

Para ter transparência na prestação de informação é essencial e importante ter ferramentas que possibilitam e efetivam esta transparência, e de forma que o cidadão possa compreender a informação repassada (GOMES FILHO, 2005).

A CGU (2011) acredita que o melhor antídoto contra a corrupção é a transparência. Esta é um mecanismo indutor de que os gestores devem agir com responsabilidade, que permitem que a sociedade tenha acesso às informações e colabore com o controle das ações de seus governantes, no intuito de checar se os recursos públicos estão sendo usados como deveriam.

Observa-se nos relatos dos autores que para ter Accountability eficaz, devem-se honrar os princípios da governança pública, como gestão pública, responsabilidade, transparência e legalidade. Dentro da gestão pública deve se atentar aos princípios básicos, como organização, planejamento, comando e controle.

\subsection{Accountability na Gestão Pública}

A Accountability surgiu em meados dos anos 1980 em países de língua inglesa e esse termo não tem uma tradução para o português o que segundo Campos (1990), causa uma dificuldade de compreensão do conceito. 


\section{Revista \\ UNEMAT de \\ v. 9 , n. 18,2020 \\ Contabilidade}

Diante da dificuldade de tradução Medeiros et al. (2013) analisaram as definições atribuídas ao termo nos artigos publicados no Brasil e concluíram não ser possível traduzir de forma literal, já que seu conceito ainda está em construção. Destacaram que termos como responsabilização e prestação de contas, são os mais citados.

Como demostrado na Figura 1 a Teoria de O’Donnell (1998), Accountability tem uma visão bidimensional, vertical e horizontal.

Figura 1: A teoria de O’Donnel

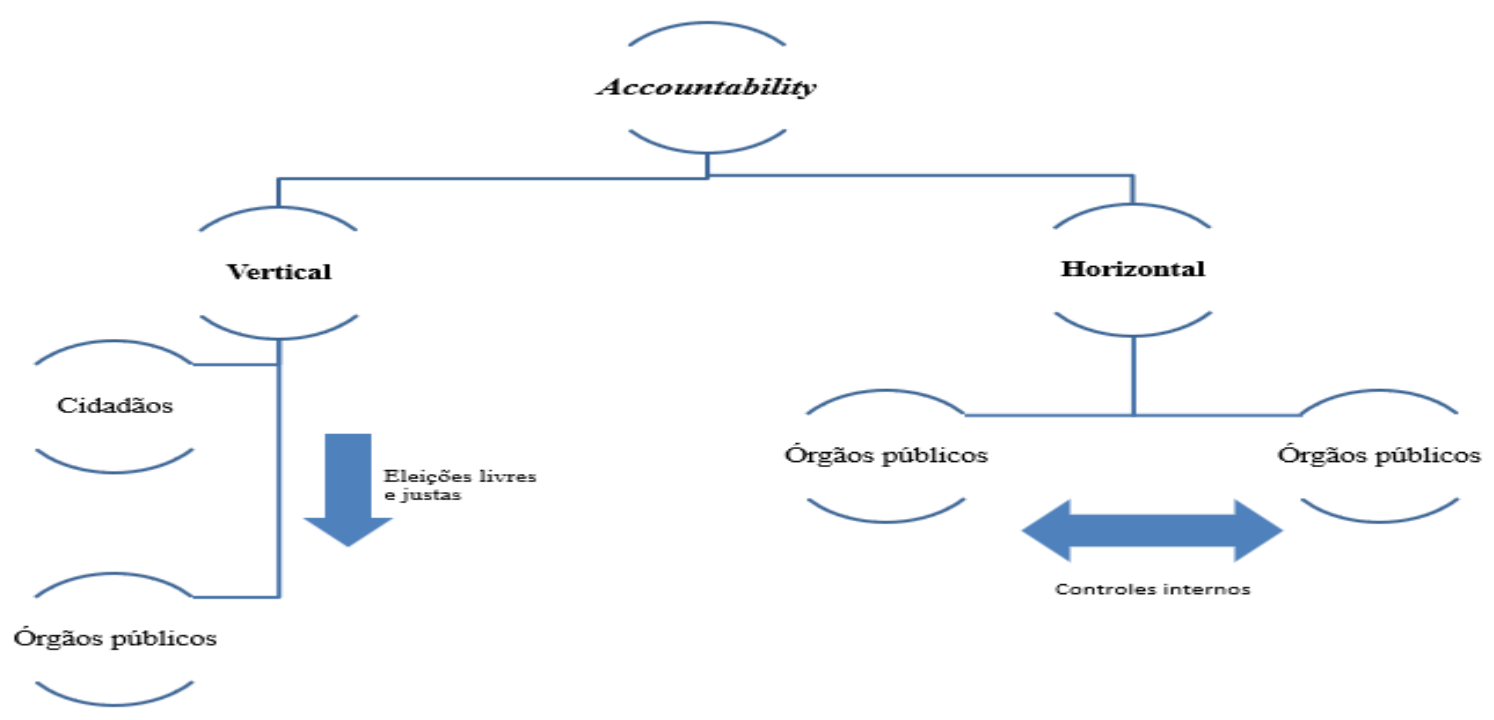

Fonte: Elaborada pelos autores com base na teoria de O’Donnell (1998).

Segundo O’Donnell (1998), Accountability vertical é caracterizada pelas eleições, livres e justas, onde os cidadãos podem premiar ou punir os mandatários na eleição seguinte. E a horizontal, existência estatal de controle que supervisiona e puni em caso de não 


\section{Revista \\ UNEMAT de \\ Contabilidade \\ v. 9, n. 18,2020}

conformidades. Os principais pontos de fragilidade estão na questão do tempo entre cada eleição (Vertical), pela corrupção e por obter vantagens ilícitas por parte das autoridades envolvidas no processo (Horizontal).

Schedler (1999) defende Accountability como a resposta dos gestores públicos aos seus atos. No entanto, deve haver a obrigatoriedade e sanções ao não cumprimento, para que a ação tenha efeito. Carneiro (2004) afirma que a necessidade por Accountability só tem sentido se remete ao espaço público, de forma a obter informação, justificativas e punições. Deve-se ocorrer como forma de cobrar respostas dos governantes em decorrência às deficiências nas informações que são passadas ao público.

No Brasil a prestação de contas é garantida desde a Constituição Federal, segundo a qual deve prestar contas “[...] qualquer pessoa física ou jurídica, pública ou privada, que utilize, arrecade, guarde, gerencie ou administre dinheiro, bens e valores públicos [...]" (BRASIL, 1988, p.01).

A evolução democrática no Brasil aconteceu no ano de 2000 e foi sancionada por meio da Lei Complementar $n^{\circ} 101 / 2000$, que trouxe grandes mudanças na gestão pública quanto ao planejamento das ações do governo, também quanto à regulação dos gastos, contribuindo significativamente para a evolução dos conceitos de responsabilidade, eficiência e transparência na gestão pública. Ao designar a divulgação em meios eletrônicos das peças orçamentárias, a Lei de Responsabilidade Fiscal possibilitou o controle social das finanças públicas, contribuindo assim para o surgimento de uma nova ordem em termos de gestão pública participativa no Brasil (CARNEIRO et al., 2010).

Os agentes responsáveis que não cumprirem as exigências impostas pela Lei Complementar $n^{\circ}$ 131/2009 e sua regulamentação poderão sofrer sanções. Entre elas, pode-se citar a perda da função pública, a suspensão dos direitos políticos no período de três a cinco 


\section{Revista \\ UNEMAT de \\ v. 9 , n. 18,2020 \\ Contabilidade}

anos, e pagamento de multa civil de até cem vezes o valor da remuneração percebida pelo agente.

\subsection{Lei Complementar $\mathrm{N}^{\circ}$ 131, de 27 de maio de 2009}

A Lei Complementar $\mathrm{n}^{\mathrm{o}}$ 131, de 27 de maio de 2009 acrescenta dispositivos à Lei Complementar $\mathrm{n}^{\circ} 101$, de 4 de maio de 2000, que estabelece normas de finanças públicas voltadas para a responsabilidade na gestão fiscal e dá outras providências. Visa determinar a disponibilização, em tempo real, de informações pormenorizadas sobre a execução orçamentária e financeira da União, dos Estados, do Distrito Federal e dos Municípios (BRASIL, 2009). A seguir a redação da Lei Complementar No 131/2009:

Art. $1^{\circ} . \mathrm{O}$ art. 48 da Lei Complementar $\mathrm{n}^{\circ}$ 101, de 4 de maio de 2000, passa a vigorar com a seguinte redação:

"Art. 48.

Parágrafo único. A transparência será assegurada também mediante:

I - Incentivo à participação popular e realização de audiências públicas, durante os processos de elaboração e discussão dos planos, Lei de diretrizes orçamentárias e orçamentos;

II - Liberação ao pleno conhecimento e acompanhamento da sociedade, em tempo real, de informações pormenorizadas sobre a execução orçamentária e financeira, em meios eletrônicos de acesso público;

III - Adoção de sistema integrado de administração financeira e controle, que atenda a padrão mínimo de qualidade estabelecido pelo Poder Executivo da União e ao disposto no art. 48-A.” (NR)

Art. $2^{\circ}$. A Lei Complementar no 101, de 4 de maio de 2000, passa a vigorar acrescida dos seguintes arts. 48-A, 73-A, 73-B e 73-C: 


\section{Revista}

UNEMAT de

v. 9, n. 18,2020

\section{Contabilidade}

“Art. 48-A. Para os fins a que se refere o inciso II do parágrafo único do art. 48, os entes da Federação disponibilizarão a qualquer pessoa física ou jurídica o acesso a informações referentes a: I - quanto à despesa: todos os atos praticados pelas unidades gestoras no decorrer da execução da despesa, no momento de sua realização, com a disponibilização mínima dos dados referentes ao número do correspondente processo, ao bem fornecido ou ao serviço prestado, à pessoa física ou jurídica beneficiária do pagamento e, quando for o caso, ao procedimento licitatório realizado;

II - Quanto à receita: o lançamento e o recebimento de toda a receita das unidades gestoras, inclusive referente a recursos extraordinários."

“Art. 73-A. Qualquer cidadão, partido político, associação ou sindicato é parte legítima para denunciar ao respectivo Tribunal de Contas e ao órgão competente do Ministério Público o descumprimento das prescrições estabelecidas nesta Lei Complementar."

“Art. 73-B. Ficam estabelecidos os seguintes prazos para o cumprimento das determinações dispostas nos incisos II e III do parágrafo único do art. 48 e do art. 48-A:

I - 1 (um) ano para a União, os Estados, o Distrito Federal e os Municípios com mais de 100.000 (cem mil) habitantes;

II - 2 (dois) anos para os Municípios que tenham entre 50.000 (cinquenta mil) e 100.000 (cem mil) habitantes;

III - 4 (quatro) anos para os Municípios que tenham até 50.000 (cinquenta mil) habitantes.

Parágrafo único. Os prazos estabelecidos neste artigo serão contados a partir da data de publicação da Lei complementar que introduziu os dispositivos referidos no caput deste artigo." 


\section{Revista \\ UNEMAT de \\ Contabilidade \\ v. 9, n. 18,2020}

Art. 73-C. O não atendimento, até o encerramento dos prazos previstos no art. 73-B, das determinações contidas nos incisos II e III do parágrafo único do art. 48 e no art. 48-A sujeita o ente à sanção prevista no inciso I do § 3o do art. 23.

A referida Lei estabelece normas de finanças públicas voltadas para a responsabilidade na gestão fiscal e dá outras providências, a fim de determinar a disponibilização, em tempo real, de informações orçamentárias e financeiras do Município (BRASIL, 2009).

Todavia, não basta que a informação esteja disponível. Por ser instrumento de tomada de decisão, para que possa se aplicar Accountability, a informação deve ser divulgada em tempo real, de forma precisa, confiável, acessível publicamente e detalhada. Caso seja apresentada de outra forma, não atinge o objetivo da transparência (ALVES, 2008).

Dentro do Accountability, o gestor público é o indivíduo responsável em prestar contas sobre normas de finanças públicas e incentiva à participação popular conforme a Lei complementar 131 art. 48 inciso I.

\subsection{Decreto $\mathrm{n}^{\circ}$ 7.185, de 27 de Maio de 2010}

O Decreto $\mathrm{n}^{\mathrm{o}} 7.185$ de 27 de maio de 2010, dispõe sobre o padrão mínimo de qualidade do sistema integrado de administração pública, no âmbito econômico, nos termos do art. 48, parágrafo único, inciso III, da Lei Complementar no 101, de 4 de maio de 2000 (BRASIL, 2010). A seguir a redação deste decreto:

\section{CAPÍTULO I}

\section{DAS DISPOSIÇÕES GERAIS}

Art. 1o A transparência da gestão fiscal dos entes da Federação referidos no art. $1^{\circ}, \S 3^{\circ}$, da Lei Complementar $n^{\circ} 101$, de 4 de maio de 2000, será assegurada mediante a observância 


\section{Revista \\ UNEMAT de \\ Contabilidade}

v. 9, n. 18,2020

do disposto no art. 48, parágrafo único, da referida Lei e das normas estabelecidas neste Decreto Art. 2o O sistema integrado de administração financeira e controle utilizado no âmbito de cada ente da Federação, doravante denominado SISTEMA, deverá permitir a liberação em tempo real das informações pormenorizadas sobre a execução orçamentária e financeira das unidades gestoras, referentes à receita e à despesa, com a abertura mínima estabelecida neste Decreto, bem como o registro contábil tempestivo dos atos e fatos que afetam ou possam afetar o patrimônio da entidade.

§ 1o Integrarão o SISTEMA todas as entidades da administração direta, as autarquias, as fundações, os fundos e as empresas estatais dependentes, sem prejuízo da autonomia do ordenador de despesa para a gestão dos créditos e recursos autorizados na forma da legislação

vigente e em conformidade com os limites de empenho e o cronograma de desembolso estabelecido.

$\S 20$ Para fins deste Decreto, entende-se por:

I - sistema integrado: as soluções de tecnologia da informação que, no todo ou em parte, funcionando em conjunto, suportam a execução orçamentária, financeira e contábil do ente da Federação, bem como a geração dos relatórios e demonstrativos previstos na legislação;

II - liberação em tempo real: a disponibilização das informações, em meio eletrônico que possibilite amplo acesso público, até o primeiro dia útil subsequente à data do registro contábil no respectivo SISTEMA, sem prejuízo do desempenho e da preservação das rotinas de segurança operacional necessários ao seu pleno funcionamento;

III - meio eletrônico que possibilite amplo acesso público: a Internet, sem exigências de cadastramento de usuários ou utilização de senhas para acesso; e 


\section{Revista}

UNEMAT de

v. 9, n. 18,2020

\section{Contabilidade}

IV - unidade gestora: a unidade orçamentária ou administrativa que realiza atos de gestão orçamentária, financeira ou patrimonial, cujo titular, em consequência, está sujeito à tomada de contas anual.

Art. 3o O padrão mínimo de qualidade do SISTEMA, nos termos do art. 48, parágrafo único, inciso III, da Lei Complementar no 101, de 2000, é regulado na forma deste Decreto.

\section{CAPÍTULO II}

\section{DOS REQUISITOS TECNOLÓGICOS}

\section{Seção I}

\subsubsection{Das Características do Sistema}

Art. 4o Sem prejuízo da exigência de características adicionais no âmbito de cada ente da Federação, consistem em requisitos tecnológicos do padrão mínimo de qualidade do SISTEMA:

I - disponibilizar ao cidadão informações de todos os Poderes e órgãos do ente da Federação de modo consolidado;

II - permitir o armazenamento, a importação e a exportação de dados; e

III - possuir mecanismos que possibilitem a integridade, confiabilidade e disponibilidade da informação registrada e exportada.

Art. 5o O SISTEMA atenderá, preferencialmente, aos padrões de arquitetura e-PING Padrões de Interoperabilidade de Governo Eletrônico, que define conjunto mínimo de premissas, políticas e especificações técnicas que regulamentam a utilização da Tecnologia de Informação e Comunicação (TIC) no Governo Federal, estabelecendo as condições de interação entre os Poderes e esferas de governo e com a sociedade em geral. 


\section{Revista \\ UNEMAT de \\ Contabilidade \\ v. 9, n. 18,2020}

\section{Seção II}

Da Geração de Informação para o Meio Eletrônico de Acesso Público

Art. 6o O SISTEMA deverá permitir a integração com meio eletrônico que possibilite amplo acesso público, assegurando à sociedade o acesso às informações sobre a execução orçamentária e financeira conforme o art. 48, parágrafo único, inciso III, da Lei Complementar no 101, de 2000, as quais serão disponibilizadas no âmbito de cada ente da Federação.

Parágrafo único. A disponibilização em meio eletrônico de acesso público deverá:

I - aplicar soluções tecnológicas que visem simplificar processos e procedimentos de atendimento ao cidadão e propiciar melhores condições para o compartilhamento das informações; e

II - atender, preferencialmente, ao conjunto de recomendações para acessibilidade dos sítios e portais do governo brasileiro, de forma padronizada e de fácil implementação, conforme o Modelo de Acessibilidade de Governo Eletrônico (e-MAG), estabelecido pela Portaria no 3, de 7 de maio de 2007, da Secretaria de Logística e Tecnologia da Informação do Governo Federal.

Art. 7o Sem prejuízo dos direitos e garantias individuais constitucionalmente estabelecidos, o SISTEMA deverá gerar, para disponibilização em meio eletrônico que possibilite amplo acesso público, pelo menos, as seguintes informações relativas aos atos praticados pelas unidades gestoras no decorrer da execução orçamentária e financeira:

I - quanto à despesa:

a) o valor do empenho, liquidação e pagamento;

b) o número do correspondente processo da execução, quando for o caso; 


\section{Revista}

UNEMAT de

v. 9, n. 18,2020

\section{Contabilidade}

c) a classificação orçamentária, especificando a unidade orçamentária, função, subfunção, natureza da despesa e a fonte dos recursos que financiaram o gasto;

d) a pessoa física ou jurídica beneficiária do pagamento, inclusive nos desembolsos de operações independentes da execução orçamentária, exceto no caso de folha de pagamento de pessoal e de benefícios previdenciários;

e) o procedimento licitatório realizado, bem como à sua dispensa ou inexigibilidade, quando for o caso, com o número do correspondente processo; e

f) o bem fornecido ou serviço prestado, quando for o caso.

O Decreto $n^{\circ} 7.185 / 2010$, que dispõe sobre o padrão mínimo de qualidade do sistema integrado de administração pública, no âmbito econômico, foi imprescindível para a criação do checklist.

A fim de complementar e reforça a aplicação do Decreto 7.185/2010, foi criada a Lei No 9.755 de 16 de dezembro de 1998. Esta dispõe sobre a criação de homepage na internet pelo Tribunal de Contas, para divulgação de dados e informações (BRASIL, 1998). Sendo esta Lei aplicada de forma mais específica para divulgação de informações e também com informações mais atualizadas com as mudanças geradas pelo acesso à internet.

\subsection{Pesquisas Anteriores Sobre o Tema}

Transcorridos dezenove anos da aprovação da Lei de Responsabilidade Fiscal, vários estudos foram realizados no Brasil com a finalidade de identificar os impactos de adoção da mesma e das normas subsequentes em todas as esferas de governo e sob diversas perspectivas. 


\section{Revista \\ UNEMAT de \\ Contabilidade}

v. 9, n. 18,2020

No Quadro 1, serão apresentados estudos relevantes, que tem como base a transparência e a gestão pública. Esta advém de pesquisas de autores nacionais que publicaram artigos científicos, após a vigência Lei de Responsabilidade Fiscal do ano 2000.

Quadro 1: Pesquisas anteriores sobre Accountability e Transparência na Gestão Pública

\begin{tabular}{|c|c|c|}
\hline Autor & Ano & Resumo \\
\hline Lock & 2003 & $\begin{array}{l}\text { Pesquisou a transparência da gestão fiscal municipal em capitais e municípios do } \\
\text { interior do Brasil, por meio de informações contábeis divulgadas na Internet, o } \\
\text { estudo revela que os municípios pesquisados não cumprem sequer minimamente a } \\
\text { legislação, o que deixa os cidadãos sem acesso às informações de caráter } \\
\text { econômico e financeiro relativas à gestão das prefeituras. }\end{array}$ \\
\hline $\begin{array}{l}\text { Monteiro, } \\
\text { Lacerda e } \\
\text { Luz }\end{array}$ & 2004 & $\begin{array}{l}\text { Pesquisaram se a sociedade se envolve de fato na fiscalização da gestão pública. } \\
\text { Através da aplicação de questionários a estudantes de graduação dos cursos da área } \\
\text { de finanças, os autores verificaram que os entrevistados não compreendem } \\
\text { claramente o processo de transparência e encontram dificuldades para } \\
\text { envolvimento social após as informações divulgadas acerca da atuação } \\
\text { governamental. }\end{array}$ \\
\hline Pinho & 2006 & $\begin{array}{l}\text { Investigou a presença da Accountability em nove portais de governos estaduais e } \\
\text { municipais no Brasil; os resultados revelam um estado ainda incipiente do uso dos } \\
\text { recursos tecnológicos de comunicação para divulgação de informações acerca da } \\
\text { atuação governamental, evidenciando a forte presença ainda de uma estrutura de } \\
\text { Estado autoritária, centralizadora e resistente à participação popular; esses } \\
\text { resultados convergem para a literatura internacional que mostra resultados } \\
\text { modestos na utilização dos recursos tecnológicos de comunicação no setor público. }\end{array}$ \\
\hline Souza et al. & 2008 & $\begin{array}{l}\text { Apuraram se os municípios mineiros utilizam a Internet, reconhecidamente um dos } \\
\text { principais meios de comunicação existente, para evidenciar as informações } \\
\text { solicitadas pela Lei de Responsabilidade Fiscal; os resultados revelam que a maior } \\
\text { parte dos municípios mineiros não possui site próprio e apontam apara uma } \\
\text { subutilização da Internet no intuito de evidenciar as informações financeiras por }\end{array}$ \\
\hline
\end{tabular}




\section{Revista}

UNEMAT de

Contabilidade

v. 9, n. 18,2020

\begin{tabular}{|l|l|l|}
\hline & & $\begin{array}{l}\text { parte dos municípios. Observaram também uma significativa diferença entre as } \\
\text { informações evidenciadas pelas diferentes mesorregiões em que foram agrupados } \\
\text { os municípios, ao que os autores atribuem fatores econômicas. }\end{array}$ \\
\hline $\begin{array}{l}\text { Ferreira et } \\
\text { of }\end{array}$ & 2014 & $\begin{array}{l}\text { Buscaram identificar se os municípios da região sudeste estavam adequados à } \\
\text { legislação vigente, no tocante a prestação de contas em meios eletrônicos. Foi } \\
\text { verificado que por se tratar da maior região em população e em geração de produto } \\
\text { interno bruto do país, a região sudeste não está atendendo aos requisitos legais e } \\
\text { não publica na íntegra sua prestação de contas. }\end{array}$ \\
\hline $\begin{array}{l}\text { Ferreira, } \\
\text { Silva, Silva }\end{array}$ & 2014 & $\begin{array}{l}\text { Buscaram identificar se os municípios da região sul estavam adequados à legislação } \\
\text { vigente, no tocante a prestação de contas em meios eletrônicos. Foi verificado que } \\
\text { houve evolução se comparados aos outros trabalhos e outras regiões do Brasil. Mas } \\
\text { para que houvesse adequação em seu sentido amplo seria necessário obter } \\
\text { resultados alinhados ao esperado pela legislação e, portanto, não estão adequadas à } \\
\text { legislação pertinente. }\end{array}$ \\
\hline
\end{tabular}

FONTE: Elaborado pelos autores.

No Quadro 1, os autores pesquisados tratam sobre a Lei de Responsabilidade Fiscal e sua aplicabilidade, Lei Complementar 131/2009 e transparência na gestão pública como formas de Accountability. Observa-se que mesmo com uma legislação em vigor, que traz diretrizes aos municípios, os mesmos ao longo dos anos continuam não cumprindo adequadamente a legislação.

\section{METODOLOGIA}

A pesquisa é caracterizada como pesquisa empírica, quanto ao objeto de estudo. É descritiva no campo de pesquisa das Ciências Sociais Aplicadas, se enquadrando nos estudos sobre Accountability e gestão pública.

No estudo foi empregado o método qualitativo e a técnica de checklist. A pesquisa foi feita no portal eletrônico institucional da Prefeitura de Pinhais, que ocorreu no mês de abril de 


\section{Revista}

UNEMAT de

v. 9, n. 18,2020

\section{Contabilidade}

2019. A partir dos dados coletados no Portal da Transparência e pesquisas bibliográficas foram feitas as análises e considerações.

A população utilizada como referência são as que residem no Estado do Paraná, que tem 399 municípios e destes, segundo o IBGE (2018), 20 municípios tem mais de 100 mil habitantes e estão obrigados a exigir a lei referida nesta pesquisa.

A amostra do estudo é o município de Pinhais, que possui 132.157 habitantes, conforme informações do IPARDES (Instituto Paranaense de Desenvolvimento Econômico e Social). A escolha de Pinhais ocorreu devido ao fato de o município estar obrigado a utilizar meios eletrônicos para prestar contas de sua gestão municipal desde maio de 2010, para atender exigência da Lei Complementar nº 131/2009.

\subsection{Instrumento da Coleta}

A coleta de dados ocorreu no portal eletrônico do município de Pinhas/Pr, com o objetivo de analisar quais os requisitos estão sendo atendidos. Os requisitos foram delimitados através da construção de um checklist como instrumento de coleta de dados, com base na análise da legislação vigente.

Foi utilizada a análise de conteúdo no portal eletrônico, conforme aponta Cooper e Schindler (2011), a análise de conteúdo protege os dados contra a percepção seletiva do pesquisador, garantindo a aplicação rigorosa de critérios de confiabilidade e validade através do instrumento de coleta de dados.

Na relação entre despesas e receitas geradas com o portal eletrônico, as despesas são gastos com manutenção das atividades e prestação de serviços aos usuários, que os gestores públicos fazem para que o Estado funcione e opere. As Receitas são recursos financeiros captados pelos gestores públicos, conforme aponta Jund, S. (2008). 


\section{Revista \\ UNEMAT de \\ Contabilidade}

v. 9, n. 18,2020

Para aplicação do checklist foram organizadas informações financeiras aos quais são informações de planejamentos dos recursos financeiros de acordo com a LC 131/2009 e o Decreto 7.185/2010. No Quadro 2 apresenta-se as informações das despesas conforme as citadas legislações.

Quadro 2: Informações das Despesas, conforme LC 131/2009 e Decreto 7.185/2010

\begin{tabular}{|c|c|}
\hline Requisito & Referência \\
\hline Tempo Real & LC $131 / 2009$ \\
\hline Informação & LC $131 / 2009$ \\
\hline Atualização & LC 131/2009 \\
\hline Períodos & LC $131 / 2009$ \\
\hline Download & LC 131/2009 \\
\hline Data da despesa & Decreto $^{\circ} 7.185 / 2010$ (Art. $2^{\circ} \S 2^{\circ}$ Inc. II) \\
\hline Valor do empenho & Decreto $\mathrm{n}^{\mathrm{o}} 7.185 / 2010$ \\
\hline Número do processo da execução & Decreto $\mathrm{n}^{\circ} 7.185 / 2010$ (Art. $7^{\circ}$ Inc. I alínea b) \\
\hline Classificação orçamentária & Decreto $\mathrm{n}^{\circ} 7.185 / 2010$ (Art. $7^{\circ}$ Inc. I alínea c) \\
\hline Identificação do beneficiário do pagamento & Decreto $\mathrm{n}^{\circ} 7.185 / 2010$ (Art. $7^{\circ}$ Inc. I alínea d) \\
\hline Procedimento licitatório realizado & Decreto $\mathrm{n}^{\circ} 7.185 / 2010$ (Art. $7^{\circ}$ Inc. I alínea e) \\
\hline Descrição do bem fornecido ou serviço prestado & Decreto $\mathrm{n}^{\circ} 7.185 / 2010$ (Art. $7^{\circ}$ Inc. I alínea e) \\
\hline Unidade gestora & Decreto $\mathrm{n}^{\circ} 7.185 / 2010$ (Art. $7^{\circ}$ Inc. I alínea e) \\
\hline
\end{tabular}

FONTE: Elaborado pelos autores.

O Quadro 2 traz alguns dos requisitos obrigatórios da Lei 131/2009 e pelo Decreto $\mathrm{n}^{\circ}$ 7.185/2010, sobre aspetos econômicos do município de Pinhais. 


\section{Revista \\ UNEMAT de \\ v. 9 , n. 18,2020 \\ Contabilidade}

No Quadro 3 apresenta-se as informações das receitas, conforme requisitos da Lei 131/2009 e decreto $7.185 / 2010$.

Quadro 3: Informações das Receitas, conforme LC 131/2009 e Decreto 7.185/2010

\begin{tabular}{|c|c|}
\hline Requisito & Referência \\
\hline Tempo Real & LC $131 / 2009$ \\
\hline Informação & LC $131 / 2009$ \\
\hline Atualização & LC $131 / 2009$ \\
\hline Períodos & LC $131 / 2009$ \\
\hline Download & LC $131 / 2009$ \\
\hline Data da posição & Decreto $n^{\circ} 7.185 / 2010$ (Art. $2^{\circ} \S 2^{\circ}$ Inc. II) \\
\hline Unidade Gestora & Decreto $n^{\circ} 7.185 / 2010$ \\
\hline Natureza da Receita & Decreto $n^{\circ} 7.185 / 2010$ \\
\hline Valor da previsão & Decreto $n^{\circ} 7.185 / 2010$ \\
\hline Valor do lançamento & Decreto $\mathrm{n}^{\mathrm{o}} 7.185 / 2010$ (Art. $7^{\circ}$ Inc. II alínea b) \\
\hline Valor da arrecadação & Decreto $\mathrm{n}^{\mathrm{o}} 7.185 / 2010$ (Art. $7^{\mathrm{o}}$ Inc. II alínea c) \\
\hline
\end{tabular}

FONTE: Elaborado pelos autores.

O Quadro 4 apresenta-se as informações financeiras, conforme requisitos da lei complementar 131/2009 e Lei 9.755/98. 


\section{Revista \\ UNEMAT de \\ Contabilidade}

v. 9 , n. 18,2020

Quadro 4: Informações Financeiras

\begin{tabular}{|l|l|}
\hline Requisito & Referência \\
\hline Tempo Real & LC 131/2009 \\
\hline Informação & LC 131/2009 \\
\hline Atualização & LC 131/2009 \\
\hline Períodos & LC 131/2009 \\
\hline Download & LC 131/2009 \\
\hline Plano Plurianual (PPA) & LC 131/2009 Art. 48 LRF \\
\hline Lei de Diretrizes & LC 131/2009 Art. 48 LRF \\
\hline Prestação de contas & LC 131/2009 Art. 48 LRF \\
\hline Relatório Resumido da Execução Orçamentária (RREO) & LC 131/2009 Art. 48 LRF \\
\hline Relatório de Gestão Fiscal (RGF) & LC 131/2009 Art. 48 LRF \\
\hline Lei Orçamentária Anual & LC 131/2009 Art. 48 LRF \\
\hline Balanço Anual do Exercício Anterior & Lei 9.755/98 (Art. 1 Inciso IV) ${ }^{\circ}$ \\
\hline
\end{tabular}

FONTE: Elaborado pelos autores.

${ }^{1}$ Lei 9.755/98 - Art. 10 O Tribunal de Contas da União criará homepage na rede de computadores Internet, com o título "contas públicas", para divulgação dos seguintes dados e informações: IV - os orçamentos do exercício da União, dos Estados, do Distrito Federal e dos Municípios e os respectivos balanços do exercício anterior (art. 112 da Lei n ${ }^{\circ} 4.320$, de 1964); 


\section{Revista}

UNEMAT de

Contabilidade

v. 9 , n. 18,2020

O Quadro 4 traz alguns dos requisitos obrigatórios sobre Lei 131/2009 e Lei 9.755/98 sobre aspectos financeiros, do município de Pinhais.

Considerando as características das variáveis, constantes no instrumento de coleta de dados, foi realizada a análise descritiva. Foi verificada disponibilização ou não das informações no portal eletrônico, conforme a Lei Complementar $n^{\circ} 131 / 2009$, Decreto $\mathrm{N}^{\mathrm{o}}$ 7.185/2010 e Lei 9.755/98. E, se tais informações estavam atualizadas.

\section{ANÁLISE E DISCUSSÃO DOS RESULTADOS}

O município de Pinhais tem área territorial de $60,840 \mathrm{~km}^{2}$, com distância $8,90 \mathrm{~km}$ da capital do Estado do Paraná, Curitiba, localizando-se na região metropolitana desta capital. Foi desmembrada em 1993, do município de Piraquara. O município tem a economia baseada na indústria, serviços e comércio, e desenvolve outras atividades econômicas, como lavoura e pecuária. A população estimada para o ano de 2019 foi de 132.157 habitantes. O IDHM Índice de Desenvolvimento Humano é 0,751 (ano de 2010). O Índice IPARDES de Desempenho municipal (IPDM) 0,7445, IPDM - Renda, emprego e produção agropecuária de 0,6145, IPDM - Educação de 0,7906, IPDM- Saúde 0,8283, sendo os indicadores IPARDES para o ano de 2016. O grau de urbanização é 100\% (IPARDES, 2020). Sendo, portanto, um município com grande desenvolvimento local e indicadores que demonstram este bom desenvolvimento em vários setores, destacando-se no cenário estadual. 


\section{Revista \\ UNEMAT de \\ v. 9 , n. 18,2020 \\ Contabilidade}

Quadro 5: Localização e limites do município de Pinhais



Fonte: IPARDES, 2020.

Destaca-se a localização do município pela proximidade com a capital do Estado do Paraná. E a proximidade com o litoral, o que favorece o desenvolvimento da economia local.

Neste tópico são apresentados os resultados da pesquisa realizada no site da Prefeitura de Pinhais, no Portal da Transparência localizado na tela inicial, na aba transparência, no período de abril de 2019, conforme pode ser visualizado na Figura 1. 


\section{Revista \\ UNEMAT de \\ v. 9 , n. 18,2020 \\ Contabilidade}

Figura 1: Portal da Transparência - Município de Pinhais/Pr

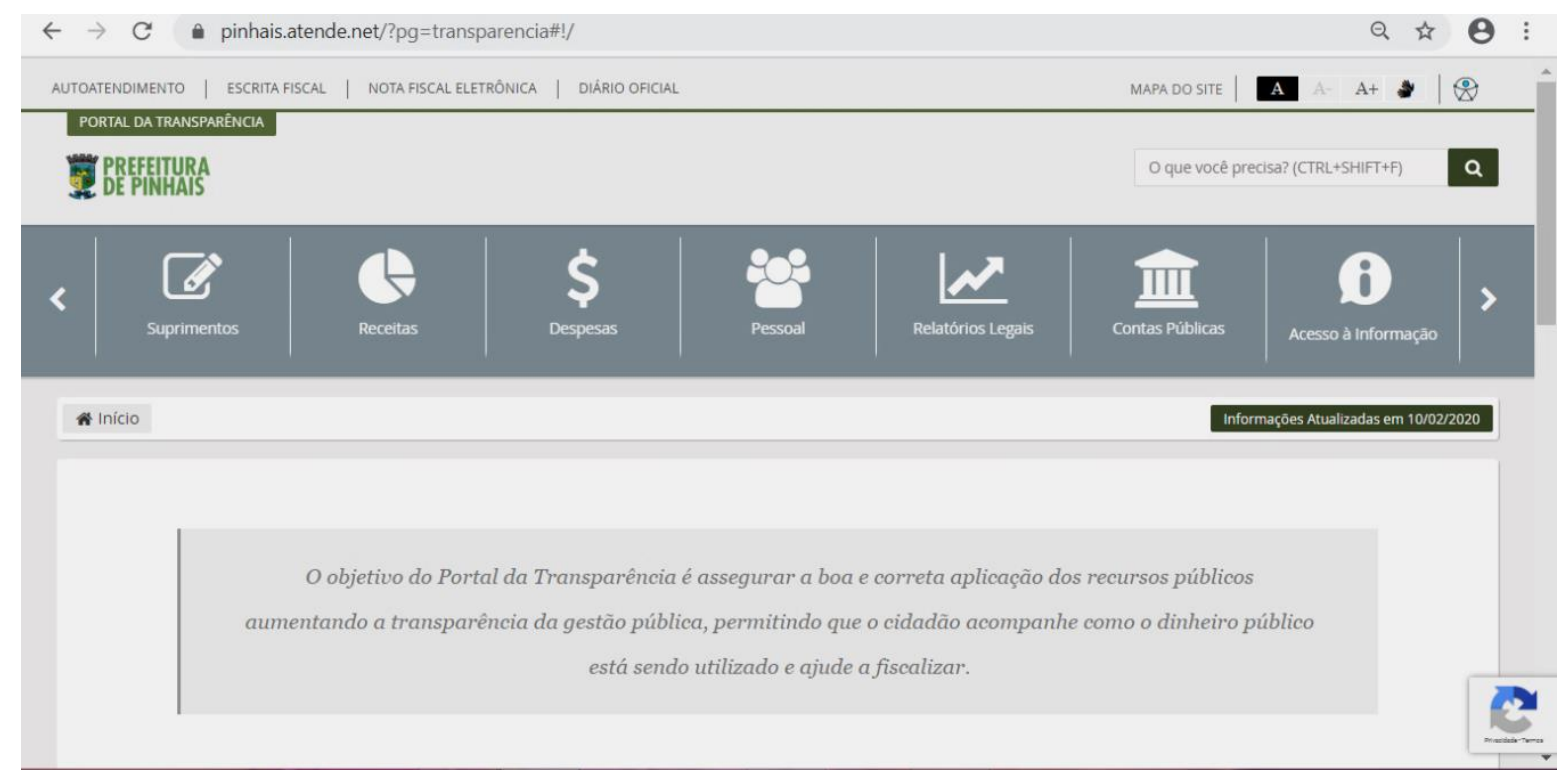

Fonte: Site Prefeitura de Pinhais (2020).

A Figura 1 apresenta o portal que disponibiliza ao usuário a opção de escolha do período para a consulta das informações, com a possibilidade de download em diversos formatos.

Dentro do portal da transparência do município de Pinhais existem diversas informações, foram selecionadas as informações de acordo com a Lei complementar 131/2009 e a escolha dos autores, que ficaram divididas entre aspectos econômicos (Receitas e Despesas) e aspectos financeiros (Informações financeiras). 


\section{Revista \\ UNEMAT de \\ v. 9 , n. 18,2020 \\ Contabilidade}

\subsection{Aspectos Econômicos}

No Quadro 6 apresenta-se checklist para verificação se há disponibilização das informações das despesas, conforme requisitos da Lei 131/2009 e decreto 7.185/2010.

Quadro 6: Informações das despesas

\begin{tabular}{|c|c|c|c|}
\hline \multirow{2}{*}{ Requisito } & \multirow{2}{*}{ Referência } & \multicolumn{2}{|c|}{ Encontrado } \\
\hline & & Sim & Não \\
\hline Tempo Real & LC 131/2009 & & $\mathrm{X}$ \\
\hline Informação & LC 131/2009 & $\mathrm{X}$ & \\
\hline Atualização & LC $131 / 2009$ & $\mathrm{X}$ & \\
\hline Períodos & LC 131/2009 & $\mathrm{X}$ & \\
\hline Download & LC 131/2009 & $\mathrm{X}$ & \\
\hline Data da despesa & $\begin{array}{l}\text { Decreto } n^{\circ} 7.185 / 2010 \text { (Art. } 2^{\circ} \S 2^{\circ} \text { Inc. } \\
\text { II) }\end{array}$ & $\mathrm{X}$ & \\
\hline Valor do empenho & Decreto $^{\circ}$ 7.185/2010 & $\mathrm{X}$ & \\
\hline Número do processo da execução & $\begin{array}{l}\text { Decreto } n^{\circ} 7.185 / 2010 \text { (Art. } 7^{\circ} \text { Inc. I } \\
\text { alínea b) }\end{array}$ & $\mathrm{X}$ & \\
\hline Classificação orçamentária & $\begin{array}{l}\text { Decreto n } \mathrm{n}^{\mathrm{O}} 7.185 / 2010 \text { (Art. } 7^{\circ} \text { Inc. I } \\
\text { alínea c) }\end{array}$ & $\mathrm{X}$ & \\
\hline Identificação do beneficiário do pagamento & $\begin{array}{l}\text { Decreto } \mathrm{n}^{\circ} 7.185 / 2010 \text { (Art. } 7^{\circ} \text { Inc. I } \\
\text { alínea d) }\end{array}$ & $\mathrm{X}$ & \\
\hline Procedimento licitatório realizado & $\begin{array}{l}\text { Decreto } \mathrm{n}^{\circ} 7.185 / 2010 \text { (Art. } 7^{\circ} \text { Inc. I } \\
\text { alínea e) }\end{array}$ & $\mathrm{X}$ & \\
\hline Descrição do bem fornecido ou serviço prestado & $\begin{array}{l}\text { Decreto } n^{\circ} 7.185 / 2010 \text { (Art. } 7^{\circ} \text { Inc. I } \\
\text { alínea e) }\end{array}$ & $\mathrm{X}$ & \\
\hline
\end{tabular}




\section{Revista \\ UNEMAT de \\ v. 9 , n. 18,2020 \\ Contabilidade}

Unidade gestora

Decreto $\mathrm{n}^{\mathrm{o}} 7.185 / 2010$ (Art. $7^{\circ}$ Inc. I

alínea e)

FONTE: Elaborado pelos autores.

O detalhamento das despesas no portal eletrônico de Pinhais apresenta-se em uma barra de ferramentas, e atendeu 92\% dos requisitos exigidos na legislação, pois dos 13 itens, 12 estão de acordo com legislação. Somente o item de tempo real não está em conformidade, pois em nenhum momento observa-se a marcação de horas nos relatórios.

No Quadro 7 apresenta-se checklist para verificação se há disponibilização das informações das receitas, conforme requisitos da Lei 131/2009 e decreto 7.185/2010.

Quadro 7: Informações das receitas

\begin{tabular}{|c|c|c|c|}
\hline \multirow{2}{*}{ Requisito } & \multirow{2}{*}{ Referência } & \multicolumn{2}{|c|}{ Encontrado } \\
\hline & & Sim & Não \\
\hline Tempo Real & LC 131/2009 & & $\mathrm{X}$ \\
\hline Informação & LC 131/2009 & & $\mathrm{X}$ \\
\hline Atualização & LC 131/2009 & $\mathrm{X}$ & \\
\hline Períodos & LC 131/2009 & $\mathrm{X}$ & \\
\hline Download & LC 131/2009 & & $\mathrm{X}$ \\
\hline Data da posição & Decreto $\mathrm{n}^{\circ} 7.185 / 2010\left(\right.$ Art. $2^{\circ} \S 2^{\circ}$ Inc. II) & & $\mathrm{X}$ \\
\hline Unidade Gestora & Decreto ${ }^{\circ} 7.185 / 2010$ & & $\mathrm{X}$ \\
\hline Natureza da Receita & Decreto ${ }^{\circ} 7.185 / 2010$ & & $\mathrm{X}$ \\
\hline Valor da previsão & Decreto ${ }^{\circ} 7.185 / 2010$ & & $\mathrm{X}$ \\
\hline Valor do lançamento & $\begin{array}{l}\text { Decreto n }{ }^{\circ} 7.185 / 2010 \text { (Art. } 7^{\circ} \text { Inc. II alínea } \\
\text { b) }\end{array}$ & $\mathrm{X}$ & \\
\hline
\end{tabular}




\section{Revista \\ UNEMAT de \\ v. 9 , n. 18,2020 \\ Contabilidade}

Valor da arrecadação

Decreto $\mathrm{n}^{\mathrm{o}} 7.185 / 2010$ (Art. $7^{\circ}$ Inc. II alínea

c)

FONTE: Elaborado pelos autores.

As receitas apresentam-se em uma barra de ferramentas e não apresentam 7 itens de forma clara e objetiva (tempo real, download, data da posição, unidade gestora, natureza da receita e valor da previsão). Observa-se no Quadro 7, que em relação às receitas, a disponibilização de informações cumpriu $36 \%$ das obrigatoriedades exigidas na Lei, do total de 11 itens analisados, portanto, não cumpriram $64 \%$ da obrigatoriedade legal.

\subsection{Aspectos Financeiros}

No Quadro 8 apresenta-se o checklist para verificação se há disponibilização de informações financeiras, conforme requisitos da Lei Complementar 131/2009 e Lei 9.755/98.

Quadro 8: Informações Financeiras

\begin{tabular}{|l|l|c|c|}
\hline \multirow{2}{*}{ Requisito } & \multirow{2}{*}{ Referência } & \multicolumn{2}{|c|}{ Encontrado } \\
\cline { 2 - 5 } & & Sim & Não \\
\hline Tempo Real & LC 131/2009 & & X \\
\hline Informação & LC 131/2009 & X & \\
\hline Atualização & LC 131/2009 & X & \\
\hline Períodos & LC 131/2009 & X & \\
\hline Download & LC 131/2009 & X & \\
\hline Plano Plurianual (PPA) & LC 131/2009 Art. 48 LRF & X & \\
\hline Lei de Diretrizes & LC 131/2009 Art. 48 LRF & X & \\
\hline Prestação de contas & LC 131/2009 Art. 48 LRF & X & \\
\hline
\end{tabular}




\begin{tabular}{|l|l|c|c|}
\hline Relatório Resumido da Execução Orçamentária (RREO) & LC 131/2009 Art. 48 LRF & X & \\
\hline Relatório de Gestão Fiscal (RGF) & LC 131/2009 Art. 48 LRF & X & \\
\hline Lei Orçamentária Anual & LC 131/2009 Art. 48 LRF & X \\
\hline Balanço Anual do Exercício Anterior & Lei 9.755/98 (Art. 1 Inciso IV) & X \\
\hline
\end{tabular}

FONTE: Elaborado pelos autores.

No Quadro 8 apresentam-se as informações financeiras disponibilizadas no Portal eletrônico da prefeitura de Pinhais, localizado na barra de ferramentas, o ícone tem o nome de relatórios legais. Verifica-se que de 12 itens, 11 estão de acordo com legislação, somente o item de tempo real não está em conformidade, pois não há marcação de horas nos relatórios. Sendo assim, no item informações financeiras a prefeitura de Pinhais cumpriu os requisitos em $92 \%$. Apesar de apresentar todos os itens a nomenclatura é diferente e complexa, sendo necessário ter conhecimento em contabilidade para realizar a análise.

Assim, os maiores impactos no aspecto econômico são dos itens de receitas, que de 11 itens pesquisados, 7 itens não estão de acordo com legislação, correspondendo a 64\%. Quanto aos itens de despesas, dos 11 itens pesquisados, somente 1 item não está de acordo com a legislação. Nos itens sobre aspectos financeiros, que totalizam 12 itens, o total de $8 \%$ não está sendo cumprido conforme a Lei.

O item informação em tempo real não estava em conformidade em todas as apresentações de dados. Em nenhum momento foi encontrado a marcação de horas nos relatórios ou tela do site. Também, a nomenclatura dos itens comparando com a Lei é diferente e complexa, sendo necessário ter conhecimento em contabilidade para realizar a análise. 


\section{Revista \\ UNEMAT de \\ Contabilidade}

v. 9, n. 18,2020

\section{CONSIDERAÇÕES FINAIS}

A pesquisa partiu da premissa que Accountability deve ser exercida pelos órgãos públicos e que há uma legislação que os obrigam. Para sua eficácia e eficiência devem honrar os princípios da Governança Pública, como gestão pública, responsabilidade, transparência e legalidade. E, que se divulgada em tempo real, de forma precisa, confiável, acessível publicamente e detalhada pode proporcionar uma informação de qualidade, instrumento na tomada de decisão beneficiando cidadãos diretamente na eleição e os gestores nos órgãos de controle.

A pesquisa alcançou seu objetivo ao evidenciar que mesmo finalizado o prazo em maio de 2010 e após nove anos da Lei complementar 131/2009, a qual estabeleceu que todas as cidades acima de 100 mil habitantes são obrigadas a atender seus dispositivos na sua integralidade, não há Accountability, em sua integridade na prefeitura de Pinhais, pois os resultados evidenciaram que nos itens sobre aspectos econômicos, que totalizam 24 itens, $33 \%$ não estão de acordo com a legislação e quanto aos aspectos financeiros 12 itens foram analisados e destes $8 \%$ não foram cumpridos, conforme a legislação vigente.

$\mathrm{Na}$ Lei está explícito que conforme o art. 73 - c, que o não atendimento, até o encerramento dos prazos previstos, das determinações sujeita o ente à sanção, entre a perda da função pública, a suspensão dos direitos políticos de três a cinco anos, e pagamento de multa civil de até cem vezes o valor da remuneração percebida pelo agente. Contudo, observou-se que neste período não houve menção em notas oficiais ou noticiário de penalização da prefeitura de Pinhais pelo não cumprimento, conforme previsto em Lei.

Considerando estudos nacionais anteriores sobre o tema, principalmente o do Ferreira et al. (2014) na região Sudeste e Sul, houve evolução no atendimento à legislação se comparados aos outros trabalhos e outras regiões do Brasil. Mas para que houvesse adequação 


\section{Revista \\ UNEMAT de \\ v. 9 , n. 18,2020 \\ Contabilidade}

em seu sentido amplo seria necessário obter resultados alinhados ao esperado pela legislação e, portanto, não estão adequadas à legislação pertinente.

A sugestão para estudos posteriores é analisar o tema Accountability em outros Municípios para verificar o cumprimento da Lei e maior disponibilidade do acesso à informação.

\section{REFERÊNCIAS}

ALVES, Diego Prandino. Acesso à informação pública no Brasil: um estudo sobre convergência e a harmonia existentes entre os principais instrumentos de transparência e de controle social. 2008 disponível em: <http://www.cgu.gov.br/ Concursos/Arquivos/6_ConcursoMonografias/Mencao-Honrosa-Profissionais.pdf>. Acesso em: 15 de mar. 2019.

BELLVER, Ana; KAUFMANN, Daniel. Transparenting Transparency: Initial Empirics and Policy Applications, World Bank Policy Research Working Paper, Washington, 2005. Disponível em: Acesso em: 15 de mar. 2019.

BICALHO, Lucídio. Transparência e Controle Social: a Lei Complementar 131/2009. Disponível em: <http://blog.inesc.org.br/2009/06/25/transparencia-e-controle-social-aleicomplementar-1312009/>. Acesso em: 03 mar. 2019. 2009.

BIZERRA, André Luiz Villagelim. Governança no setor público: a aderência dos relatórios de gestão do Poder Executivo municipal aos princípios e padrões de boas 


\section{Revista \\ UNEMAT de \\ v. 9 , n. 18,2020 \\ Contabilidade}

práticas de governança. 2011. 124f. Dissertação (Mestrado em Ciências Contábeis) Faculdade de Administração e Finanças, Universidade do Estado do Rio de Janeiro, Rio de Janeiro, 2011.

BRASIL. Constituição da República Federativa do Brasil, 1988. Disponível em http://www.planalto.gov.br/ccivil_03/constituicao/constituicao.htm.

Decreto $\mathbf{n}^{0}$ 7.185, de 27 de maio de 2010. Disponível em: http://www.planalto.gov.br/ccivil_03/_ato2007-2010/2010/decreto/d7185.htm. Acesso em: 27 mar. 2019.

Lei Complementar $n^{\circ}$ 101, de 4 de maio de 2000. Disponível em: http://www.planalto.gov.br/ccivil_03/leis/lcp/lcp101.htm. Acesso em: 27 mar. 2019.

Lei Complementar $n^{0}$ 131, de 27 de maio de 2009. Disponível em: http://www.planalto.gov.br/ccivil_03/leis/lcp/lcp131.htm. Acesso em: 27 mar. 2019.

Lei n. 9.755 de 16 de dezembro de 1998 . <http://www.planalto. gov.br/ccivil_03/Leis/L9755.htm>. Acesso em: 27 mar. 2019.

CAMPOS, Ana Maria. Accountability: Quando poderemos traduzi-la para o Português? Revista de Administração Pública. Vol. 24, n. 2, p. 30-50, fev./abr. 1990. 


\section{Revista \\ UNEMAT de \\ v. 9 , n. 18,2020 \\ Contabilidade}

CARNEIRO, Alexandre de Freitas; et al. A transparência na Gestão pública: Um estudo de sua aplicabilidade no Município de Vilhena. Ensaios de Gestão Pública. 2010. Disponível em: <http://www.letraviva.net/arquivos/Ensaios_de_Gestao_Publica.pdf>. Acesso em: 20 mar. 2019.

CARNEIRO, C. B. L.. Governança e Accountability: algumas notas introdutórias. Belo Horizonte: Escola de Governo da Fundação João Pinheiro. 2004. Disponível em: < http://www.eg.fjp.mg.gov.br/index.php/component/docman/ doc_download/286-governancae-Accountability-algumas-notas-introdutorias >. Acesso em: 20 mar. 2019.

CONTROLADORIA GERAL DA UNIÃO (CGU). Acesso à informação pública: uma introdução à Lei $\mathbf{n}^{\circ}$ 12.527, de 18 de novembro de 2011. Cartilha editada pela CGU. Disponível em <http://www.cgu.gov.br/>. Acesso em: 10 mar. 2019.

COOPER, D. R.; SCHINDLER, P. S. Métodos de pesquisa em Administração. 7 ed. Porto Alegre: Bookman, 2003.

FERREIRA, C. D.; et al. Accountability da gestão pública municipal na região sudeste e a adequação à lei complementar 131/2009. XI Congresso USP Iniciação Científica em Contabilidade, 2014.

FERREIRA, C. D.; SILVA, G. C; SILVA, E. K. Accountability da gestão pública municipal na região sul por meios eletrônicos e a adequação à lei complementar 


\section{Revista \\ UNEMAT de \\ v. 9 , n. 18,2020 \\ Contabilidade}

131/2009. XVI Engema Encontro Internacional sobre Gestão Empresarial e Meio Ambiente, 2014.

GOMES FILHO, A.B. O desafio de implementar uma gestão pública transparente. Congreso internacional del clad sobre la reforma del estado y de la administración pública, X, Santiago,2005.

HARMON, M. M.; MAYER, R. T. Teoria de la organización para la administración pública. México: Colegio Nacional de Ciências Políticas y Administración Pública A. C./ Fondo de Cultura Económica, 1999.

IPARDES - Ipardes Paranaense de Desenvolvimento Econômico e Social. Caderno Estatístico Município de Pinhais. 2020. Disponível em: < http://www.ipardes.gov.br/cadernos/MontaCadPdf1.php?Municipio=83320 $>$. Acesso em: 10 de Fevereiro de 2020.

JUND, S. (2008). Administração, Orçamento e Contabilidade Pública (3rd ed.). Rio de Janeiro: Elsevier. Brasil. (2007). Receitas públicas: manual de procedimentos (p. 233). Brasília: STN/Coordenação-Geral de Contabilidade.

KISSLER, L.; HEIDEMANN, F. G. Governança pública: novo modelo regulatório para as relações entre Estado, mercado e sociedade. Revista de Administração Pública, v. 40, n. 3, mai.jun. 2006. 


\section{Revista \\ UNEMAT de \\ v. 9 , n. 18,2020 \\ Contabilidade}

KONDO, S. et al. Transparência e Responsabilização no Setor Público: Fazendo Acontecer. Ministério do Planejamento/Brasília, SEGES: 2002.

LOCK, F. N. Transparência da gestão municipal através das informações contábeis divulgadas na internet. Dissertação de mestrado, Universidade Federal de Pernambuco. Recife, PE, Brasil, 2003.

MEDEIROS, A. K., Crantschaninov, T. I., \& Silva, F. C. (2013). Estudos sobre Accountability no Brasil: meta-análise de periódicos brasileiros das áreas de administração, administração pública, ciência política e ciências sociais. Revista de Administração Pública.

MONTEIRO, A., LACERDA, M. M. \& LUZ, R. S. A transparência da gestão fiscal na administração pública sob a ótica da sociedade. Monografia de especialização. Universidade Federal da Bahia, BA, Brasil, 2004.

O’DONNEL, Guillermo. Democracia Delegativa. Novos Estudos, São Paulo, n. 31, p.25-49, out, 1991.

PEREIRA, Cláudia. A contribuição do Tribunal de Contas da União para o aprimoramento do controle social: o caso dos conselhos de alimentação escolar. 2004. Disponível em: < ttps://portal.tcu.gov.br/biblioteca-digital/a-contribuicao-do-tribunal-de- 


\section{Revista \\ UNEMAT de \\ v. 9 , n. 18,2020 \\ Contabilidade}

contas-da-uniao-para-o-aprimoramento-do-controle-social-o-caso-dos-conselhos-de-

alimentacao-escolar.html>. Acesso em: 27 mar. 2019.

PINHO, J. A. G. Accountability em portais estaduais e municipais no Brasil: realidades distantes das promessas. In: II Encontro de Administração Pública e Governança, São Paulo, 2006.

PREFEITURA DE PINHAIS. Portal Eletrônico. 2019. Disponível em: < https://pinhais.atende.net/ >. Acesso em: 10 de Fev. 2020.

SILVA, José Afonso. Curso de Direito Constitucional Positivo. $28^{\circ}$ edição. Editora Malheiros. São Paulo, 2007, p.9. SILVA, L.M. Contabilidade governamental: um enfoque administrativo. 8. ed. São Paulo: Atlas, 2009.

SOUZA, A. A. et. al. Evidenciação contábil nos municípios mineiros: atendimento ao artigo 48 da Lei de Responsabilidade Fiscal. Congresso Brasileiro de Contabilidade, Gramado, RS, 2008.

SCHEDLER, A. Conceptualizing Accountability. In: A. Schedler, L. Diamond, \& M. F. Plattner, The Self-Restraining State: Power and Accountability in New Democracies (pp. 1328). Boulder, Colorado : Lynne Rienner Publishers.

WALDO, Dwight. O estudo da administração pública. 2. ed. Rio de Janeiro: FGV, 1971. 